DE83 012471

\title{
RELEASE OF VOLATILE FISSION PRODUCTS FROM URANIUM DIOXIDE \\ Dominique Bayen
}

(M. S. Thesis)

\author{
Materials and Molecular Research Division \\ Lawrence Berkeley Laboratory \\ and Department of Nuclear Engineering \\ University of California \\ Berkeley, CA 94720
}

\begin{abstract}
DISCLAIMER
This report was prepared as an account of work sponsored by an agency of the United States Government. Neither the United States Government nor any agency thereof, nor any of their employees, makes any warranty, express or implied, or assumes any legal liability or responsibility for the accuracy, completeness, or uselulness of any information, apparatus, product, or process disclosed, or represents that its use would not infringe privately owned rights. Reference hertin to any specific commercial product, process, or service by trade name, trademark, manufacturer, or otherwise does not necessarily constitute or imply its endorsement, recommendation, or favoring by the United States Government or any agency thereof. The views and opinions of authors expressed herein do not necessarily state or reflect those of the United Slates Government or any agency thereof.
\end{abstract}

This work was supported by the Director, Office of Energy Research, office of Basic Energy Sciences, Materiais Sciences Division of the U. S. Department of Energy under Contract No. DE-ACO3-76SF00098. 
RELEASE OF VOLATILE FISSION PRODUCTS FROM URANIUM DIOXIDE Contents

Page

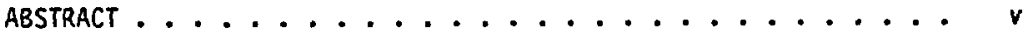

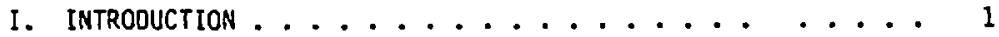

II. experimental ...................... 4

1. Experiment General Description ........ 4

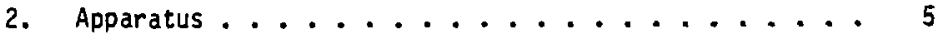

3. Specimen Preparation ........... 8

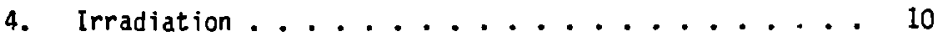

5. Gamna-detection ................. 10

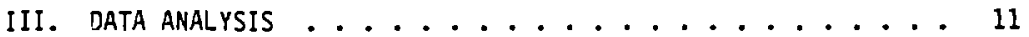

1. Spectroscopy .................. 11

2. Fractional Release Evaluation ......... 16

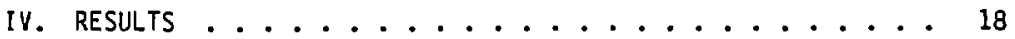

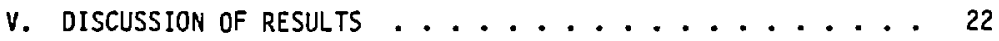

1. The Equivalent Sphere Model .......... 22

2. Square-Root-of-t Law. ............. 24

3. Temperature Dependence of the Diffusion

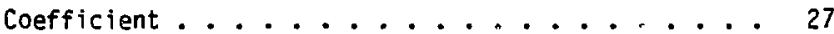

4. Equivalent Sphere Radius ............ 29

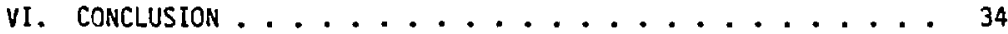

APPENDIX: FRACTIONAL RELEASE EVALUATION AND ASSOCIATED ERRORS . . 35

1. Peaks Areas Determination and Statistic Errors .... 35

2. Correction Coefficient Determination and Errors ... 35

3. Fraction Retained - Evaluation and Errors ...... 38 
Page

4. Practical Example of Fractional Release and

Error Determination ........... 40

5. Improvement of Experimental Method .........445

REFERENCES .......................... 46

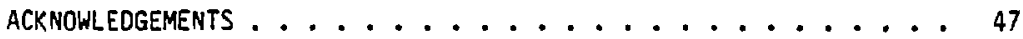




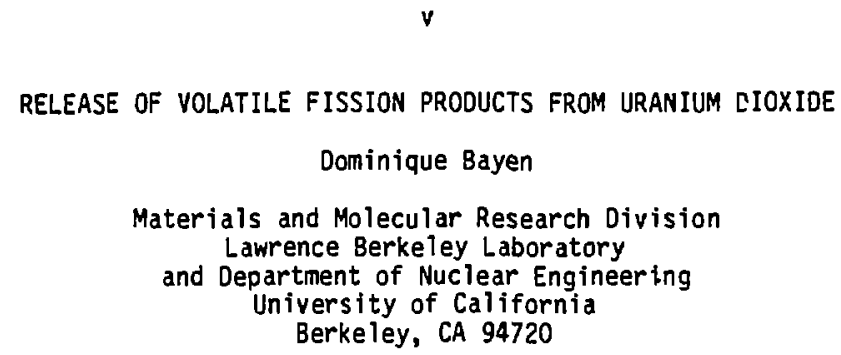

\section{ABSTRACT}

Post-irradiation anneal experiments have been used to determine the release of iodine and tellurium from lightly irradiated $\mathrm{UO}_{2}$ samples maintained at stoichiometry. The applicability of the equivalent-sphere model of diffusion to release of fission gases has been tested.

Diffusion coefficients and activation energies have been evaluated. The diffusion coefficient of Te 132 at $1400^{\circ} \mathrm{C}$ was found to be of an order-of-magnitude larger than that of I 131. This result may be of importance for an understanding of the pellet-cladding interaction and for a better evaluation of the source term for fission-product release under accident conditions.

Qualitatively, the influence of the stoichiometry on the release of $\mathrm{Xe}_{\mathrm{e}}$ 133, I 131, and Te 132 has been established. 


\section{ACKNOWLEDGEMENTS}

I wish to express my gratitude to Professors Donald R. 01ander and Stanley G. Prussin of the Department of Nuclear Engineering for their guidance from the beginning.

I would like to thank Professor M. Balooch for his support in many ways.

I would like also to thank Dan Winterbauer and John qustin for fabricating needed parts and all the reactor staff for irradiating sampies.

I wish to dedicate this work to Christine, my wife.

This work was supported by the Director, Office of Energy Research, Office of Basic Energy Sciences, Materials Sciences Division of the U. S. Department of Energy under Contract No. DE-AC03-765F00098.

This report was done with support from the Department of Energy. Any conclusions or opinions expressed in this report represent solely thase of the zuthor(s) and not necessarily those of The Regents of the University of California, the Lawrence Berkeley Laboratory or the Department of Energy.

Reference to a company or product name does not imply approval or recommendation of the product by the University of Californis or the U.S. Depanment of Energy to the exclusion of others that may be suitable. 


\section{INTRODUCTION}

The release of volatile fission products from irradiated fuel is of importance for a better understanding of pellet-cladding interaction and for a better estimation of release rates during normal nuclear power plant operation and in accident situations.

From a safety point of view, iodine release evaluation appears to be of primary interest for two reasons:

(1) radioiodine is expected to be a major contributor to public radiation exposure in the event of an atmospheric release.

(2) current regulatory accident analys is procedures focus mainly on iodine.

As data on xenon and tellurium were also available from the same set of experiments, attention was also focused on these radionuclides. The diffusion of rare gases in $\mathrm{UO}_{2}$ has been the subject of a large number of experimental investigations. Notwithstanding this effort, reliable values for the diffusion coefficients at temperatures of interest $\left(>1000^{\circ} \mathrm{C}\right)$ are still unavailable. Lawrence (1) has reviewed the literature through 1977 and has identified variables which appear to exert large effects on the release of the rare gases. (At the present time, differentiation between the release properties of krypton and xenon has not been possible and the data on rare gas release have been treated as a single set.) With respect to postirradiation anneal experiments, the following variables were identified; 
1) st:jichiometry of the $\mathrm{UO}_{2}$ chosen for the experiment

2) carrier gas composition. Depending on the environment, it is possible that a significant change in stoichiometry could occur during the course of measurement. In many experiments, the $\mathrm{UO}_{2}$ is heated in a furnace and the released volatile fission products (trace quantities) are conducted to a collector by flowing helium, hydrogen or a mixture of these. In others, heating took place in a vacuum.

3) the density and form of the solid (i.e., single crystal, sintered, fused, powdered)

4) burnup.

Measurements on fission gas release during the course of irradiation in-reactor are considerably more complex and subject to additional variables that can affect the rate of release of volatiles. Lawrence [1] indicates that data from such in-core experiments depend upon the power rating and, possibly, vaporization for those experiments of long duration.

All of these factors have not been controlled or precisely defined in most experiments. For the data reviewed by Lawrence, derived diffusion coefficients for xenon at a standard temperature of $1400^{\circ} \mathrm{C}$ show about six orders of magnitude variation. Through a search for correlations based on the variables noted above, Lawrence (1) was able to account roughly for the effects due to burnup and stoichiometry. Unfortunately, even with these corrections on the data from postirradiation anneal experiments (thought to be subject to fewer 
uncertainties than the in-core results), the data set still showed very large scatter. Treating the data as a set normally distributed in the logarithm of the diffusion coefficient, the one sigma limits covered a range of two orders of magnitude.

A very few sets of data exist on iodine and tellurium. Turnbull et a1. [2] studied in-pile release of iodine, whereas Peehs et al. [3] examined lodine and cesium behavior in post-irradiation anneal experiments. In both cases, the amount of iodine released from a fuel sample was evaluated by measuring the activity of I-130 or I-129 trapped by a charcoal filter in Ref. 2 or by a liquid-nitrogen cooled surface in Ref. 3.

As iodine is very active chemically it is quite difficult to insure complete collection of the volatilized material. As a result we have chosen to measure the fraction of a particular fission product retained in a specimen following an anneal. The method is based on the assumption (proven experimentally) that once released, no fission products return to the specimen. Thus the fractional release is one minus the fraction retained. 


\section{EXPERIMENTAL}

\section{Experiment General Description}

Samples were prepared from depleted $\mathrm{UO}_{2}$ pellets sliced into small wafers. Before the irradiation, they were reduced to stoichiometry $(0 / \mathrm{U}=2.00)$ by heating for 3 hours at $1750^{\circ} \mathrm{C}$ in the presence of $\mathrm{H}_{2}$ at a pressure of $1 \mathrm{~atm}$. After reduction and before irradiation, samples were kept under vacuum $\left(10^{-3}\right.$ Torr $)$. To avoid oxidation, the samples were irradiated under an inert atmosphere. Samples were placed into sealed plastic bags filled with helium. The "Lazy Susan" capsules used for the irradiations in the UCB TRIGA nuclear reactor were also filled with helium.

As relative measurements were to be accomplished, wafers were irradiated in pairs. In the following discussion the wafer which is annealed is called the "sample" and the other is called the "standard". Sample and standard were placed very close together during irradiation in order to receive the same flux and hence the same fission product production. Depending on the weight of the samples, the irradiation time varied from 10 to 25 minutes in order to produce roughly the same number of fissions (5 $\times 10^{12}$ fissions) and to obtain approximately $2 \mu \mathrm{Ci}$ of I 131 after 8 days of cooling following irradiation.

Irradiated wafers were kept in the reactor pool for $1 / 2$ hour and then, when the dose-rate was down to $300 \mathrm{mrem} / \mathrm{hr}$ at 1 foot, transferred a shielded glove-box. Argon flow was maintained in the glove-box to avoid oxidation of wafers during the cooling period. 
After 8 days, sufficient decay had occurred and the dose-rate was reduced to $20 \mathrm{mrem} / \mathrm{hr}$ at one inch. Handling could then take place:

- count both sample and standard with the Ge(Li) detector.

- insert and heat up the sample in the furnace, usually under flowing $\mathrm{H}_{2}$ (at temperatures ranging from 1400 to $1700^{\circ} \mathrm{C}$ ) for times between $1 \mathrm{hr}$ and $9 \mathrm{hrs}$ ).

Two methods were used to evaluate the fractional release:

- direct measurement: comparison of $\mathrm{I}^{131}, \mathrm{Xe}^{133}, \mathrm{Te}^{132}$ activities in the sample before and after annealing.

- relative meassurement: comparison of $\mathrm{I}^{131}, \mathrm{Xe}^{133}, \mathrm{Te}^{132}$ activities of the standard to that of the sample after heating.

\section{Apparatus}

Figure 1 depicts the overall system which was used for wafer reduction and irradiated sample annealing. The gas lines were 1/4 inch 0.D. Stainless steel tube. Only jwagelock-type fittings were used for connections. During reduction or annealing, hydrogen was passed through a liquid nitrogen-cooled activated charcoal trap. For anneal experiments, $\mathrm{H}_{2}$ was passed through a charcoal filter cooled by refrigerated methyl alcohol before exhausting into the reactor vent system.

Shown in Fig. 2 is a detailed view of the Brew furnace. The $\mathrm{UO}_{2}$ specimens were placed inside a molybdenum crucible which was $2.5 \mathrm{~cm}$ $0 . D$. and $15 \mathrm{~cm}$ long. A tungsten wire sample holder was designed to accommodate several wafers in an upright position. During reduction or annealing hydrogen was fed at the top of the crucible. Zirconium chips were placed above the specimen as shown in Fig. 2 in order to 


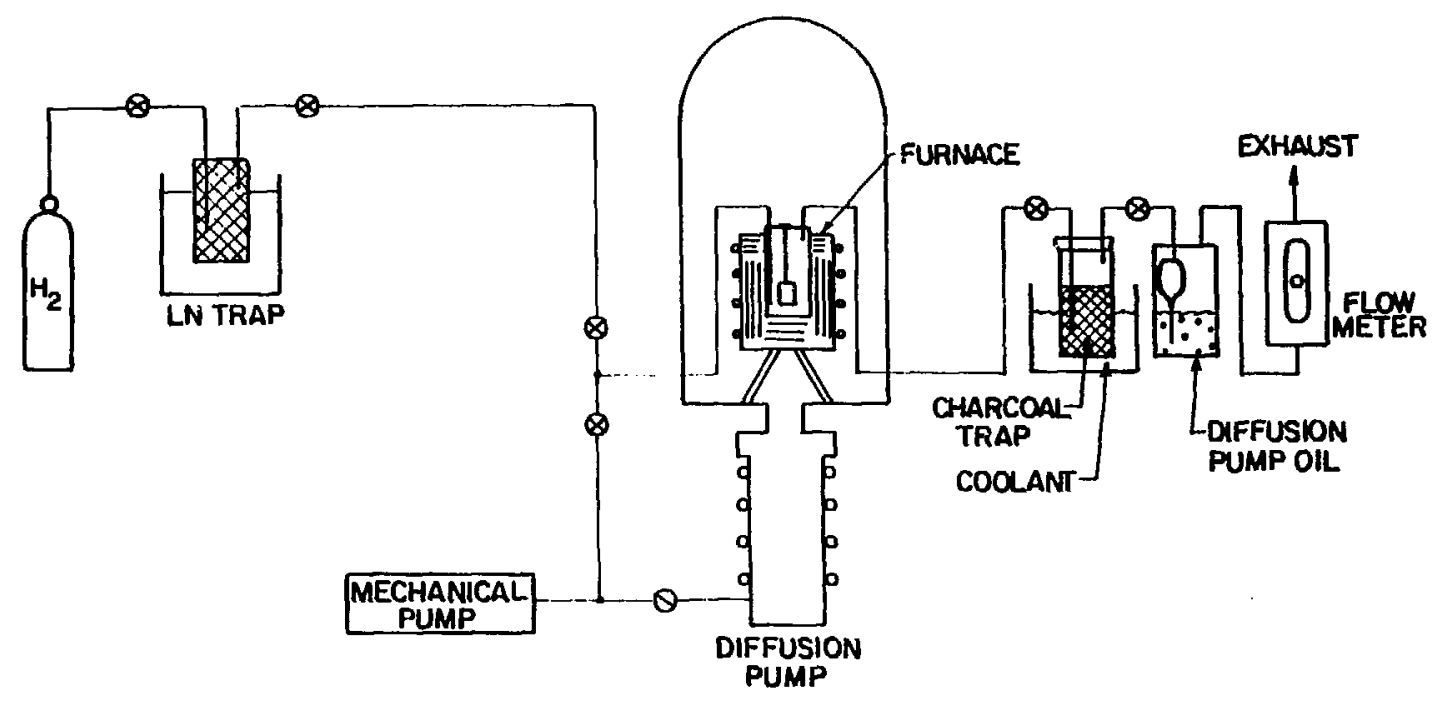

o

XBL 8210-6758

Fig. 1. Flow diagram of release apparatus. 


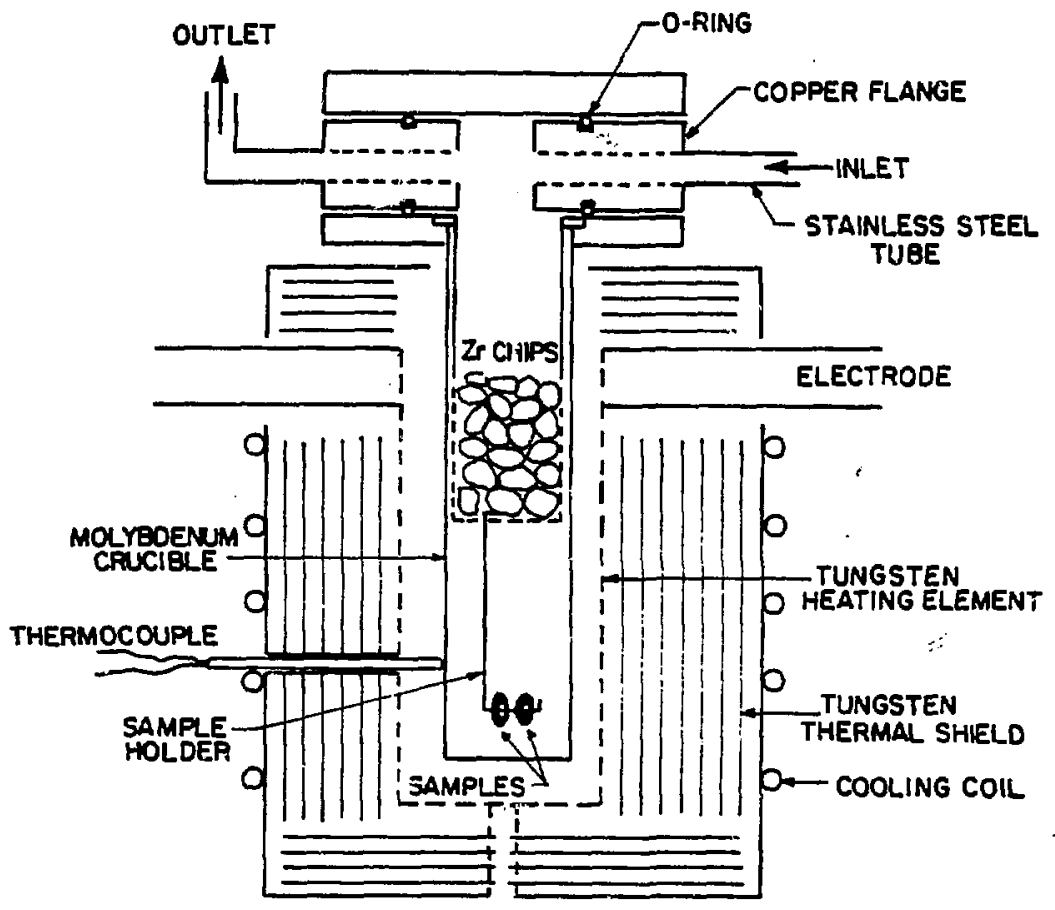

XEL8210-6737

Fig. 2. Furnace for annealing of irradiated samples. 
decrease the oxygen concentration, as $Z r$ is a strong oxygen getter at high temperature. In addition the $\mathrm{Zr}$ acts as a radiation shield and as a trap for reactive fission products released from the specimen.

The entire furnace was contained in a bell jar which was under vacuum during operation (to prevent oxidation of the furnace heating element). A pressure of $10^{-6}$ Torr could be obtained using a $15 \mathrm{~cm}$ diffusion pump. Curing furrace operation a pressure of $(5-10) x$ $10^{-6}$ torr could be maintained. The temperature was measured by a W3\%Re - W25\%Re thermocouple adjacent to the crucible. Because the thermocouple was located outside of the crucible (see Fig. 2) calibration with a thermocouple placed inside the crucible was necessary. Figure 3 shows the calibration curve.

\section{Specimen Preparation}

Depleted $\mathrm{UO}_{2}$ pellets $(0.2 \% \mathrm{U}-235) 1.05 \mathrm{~cm}$ in diameter, $1.5 \mathrm{~cm}$ high with a $0.5 \mathrm{~cm}$ diameter hole in the center were provided. Disks 0.6 to $1.4 \mathrm{~mm}$ thick were sliced from the pellets.

Single crystal $\mathrm{UO}_{2}$ pellets were provided. These were sliced into $1 \mathrm{~mm}$ thick wafers.

As mentioned before, oxide stoichiometry appears to be a very sensitive parameter for fission gas release [1]. Reduction of specimens may be accomplished in hydrogen, but this technique requires removal of oxygen and water [4]. $\mathrm{A} \mathrm{H}_{2}$ stream of $5 \mathrm{cc} / \mathrm{s}$ was maintained. For these conditions, the stoichiometric state should be reached after 3 to $4 \mathrm{hrs}$ at $1750^{\circ} \mathrm{C}$. Higher temperatures should not be used for grain growth may then occur, or reduction to $\mathrm{UO}_{2-\mathrm{x}}$ could take place. 


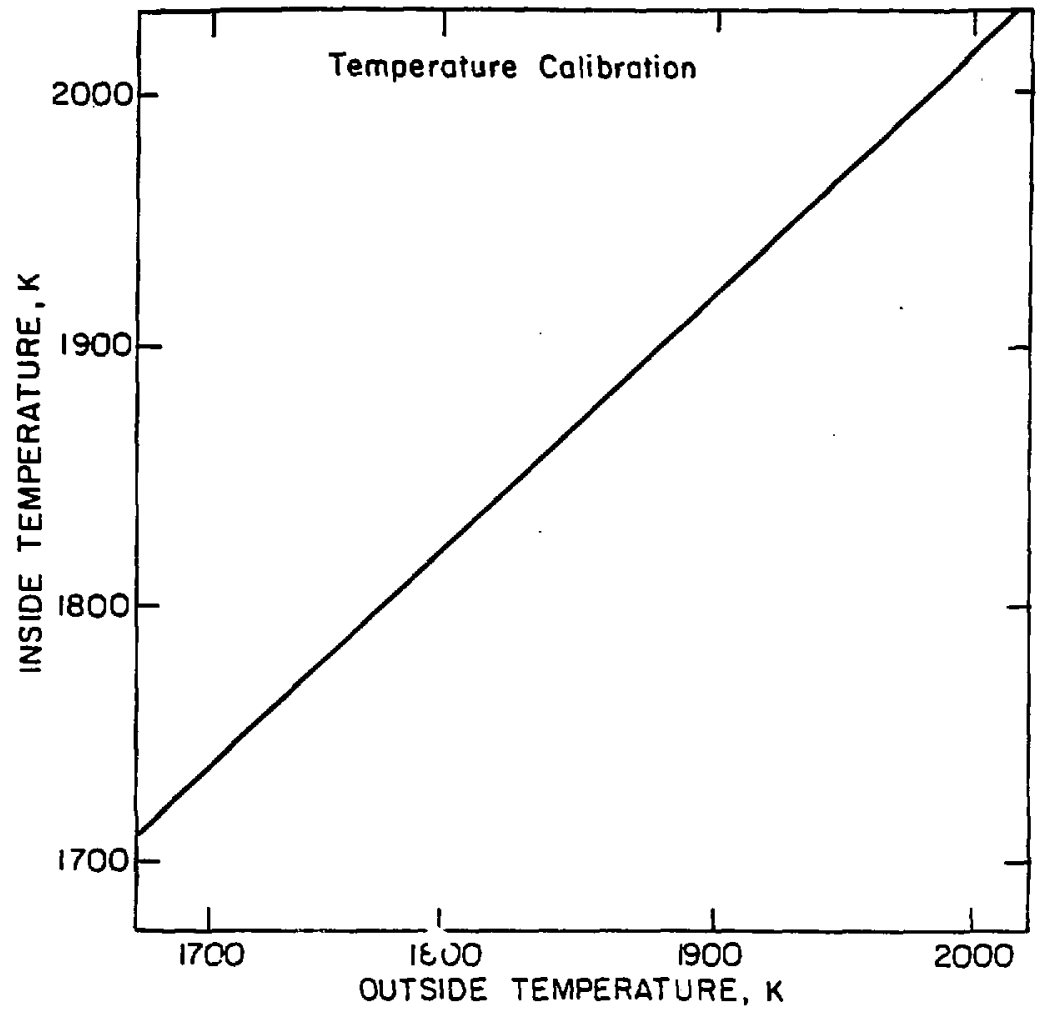

XEL B $210-6741$

Fig. 3. Calibration of the outer themocouple against a themocouple inside the crucible at the elevation of the sample. 
4. Irradiation

Irradiations were performed in the UCB TRIGA reactor in Lazy Susan capsules. The number of fissions $F$ may he easily computed for each by:

$$
F=q \times \sigma_{f} \times N_{f} \times b \times v \times t
$$

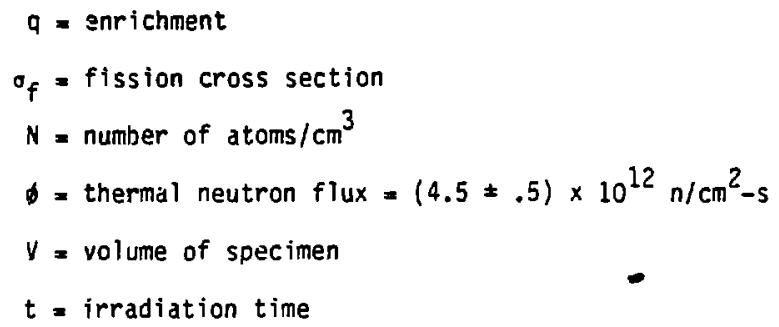

5. Gamma-Detection

A $G e(L i)$ detector was used. Before the beginning of the set of experiments, amplifiers were adjusted to get the best possible resolution, which was $2 \mathrm{kev}$ at $1.333 \mathrm{Mev}$. Then an energy calibration with known radionuclides was performed. As release evaluations were accomplished only with relative measurements, careful attention was given to the position of sample and standard in front of the detector. For this purpose a rack with 30 different numbered positions and a sample holder were designed to insure that sample and standard were counted at exactly the same position in front of the detector. 


\section{DATA ANALYSSIS}

\section{Spectroscopy}

After samples had been irradiated, radioactive decay of selected r-rays peaks was followed and half-lives computed. With a listing of the major peaks in irradiated $\mathrm{UO}_{2}$ given in [5], identification of nuclides present was possible. These are shown in Table 1 and are also plotted in Figs. 4 and 5.

For accurate peak area determination, two conditions should be met:

1) The peak must be clean: No other peak at the same energy for the time period of interest. Fortunately, this was the case for the $364 \mathrm{keV}$ line of I 131, the $81 \mathrm{keV}$ line of $X e 133$ and the $772.7 \mathrm{keV}$ line of I 132. But, for example for the period from 8 to 28 days after irradiation, data from the $228.2 \mathrm{keV}$ line of Te 132 and the $668 \mathrm{keV}$ line of I 132 were useless. In order to evaluate peak areas in these cases, sophisticated spectrum analysis would have been required.

2) Precursors of the nuclide of interest should have either a short half-life (then release of the daughter can be measured) or a long half-life (then release of the precursor can be determined) compared to the daughter's.

Chains of interest are the following: 
Table 1: Irradiated $\mathrm{UO}_{2}$ peaks.

\begin{tabular}{|c|c|c|c|c|}
\hline $\begin{array}{l}\text { Channel } \\
\text { number }\end{array}$ & $\begin{array}{c}\text { Energy } \\
\mathrm{keV}\end{array}$ & $\begin{array}{l}\text { Nuclide } \\
\text { and } \\
\text { half life }\end{array}$ & $\begin{array}{l}\text { Relative intensity } \\
\text { after } 21 d \text { (peak max } \\
\text { height/Background) }\end{array}$ & Remarks \\
\hline 150 & 81 & Xe $133(5.35 d)$ & 1.7 & \\
\hline 449 & 228.2 & Te $132(78.3 \mathrm{~h})$ & 5.4 & $\begin{array}{l}\leftarrow \text { not clean } \\
\text { (Np } 239 \text { peak) }\end{array}$ \\
\hline 551 & 276.6 & Np 239(2.35d) & 5.8 & \\
\hline 657 & 328.7 & La $140(12.78 d)$ & 6.0 & \\
\hline 731 & 364.5 & I $131(8.04 d)$ & 11.2 & \\
\hline 985 & 487 & La 140 & 18.9 & \\
\hline 1006 & 497 & Ru $103(39.4 d)$ & 11.1 & \\
\hline 1360 & 668 & I 132 & 5.0 & $\leftarrow$ not clean \\
\hline 1477 & 724 & $\operatorname{2r} 95(64 d)$ & 16.0 & \\
\hline 1545 & 756.7 & $\operatorname{lr} 95$ & 20.0 & \\
\hline 1564 & 765.8 & No $95(35 d)$ & 13.6 & $\begin{array}{l}\& \text { daughter } \\
\text { of the } \\
65 \mathrm{~d} \mathrm{Zr} 95\end{array}$ \\
\hline 1578 & 773 & I 132 & 7.0 & \\
\hline 1667 & 815.7 & La 140 & & $\begin{array}{l}\stackrel{\text { not clean }}{(T c 96)} \\
\end{array}$ \\
\hline 3290 & 1596 & La 140 & 140.0 & \\
\hline
\end{tabular}




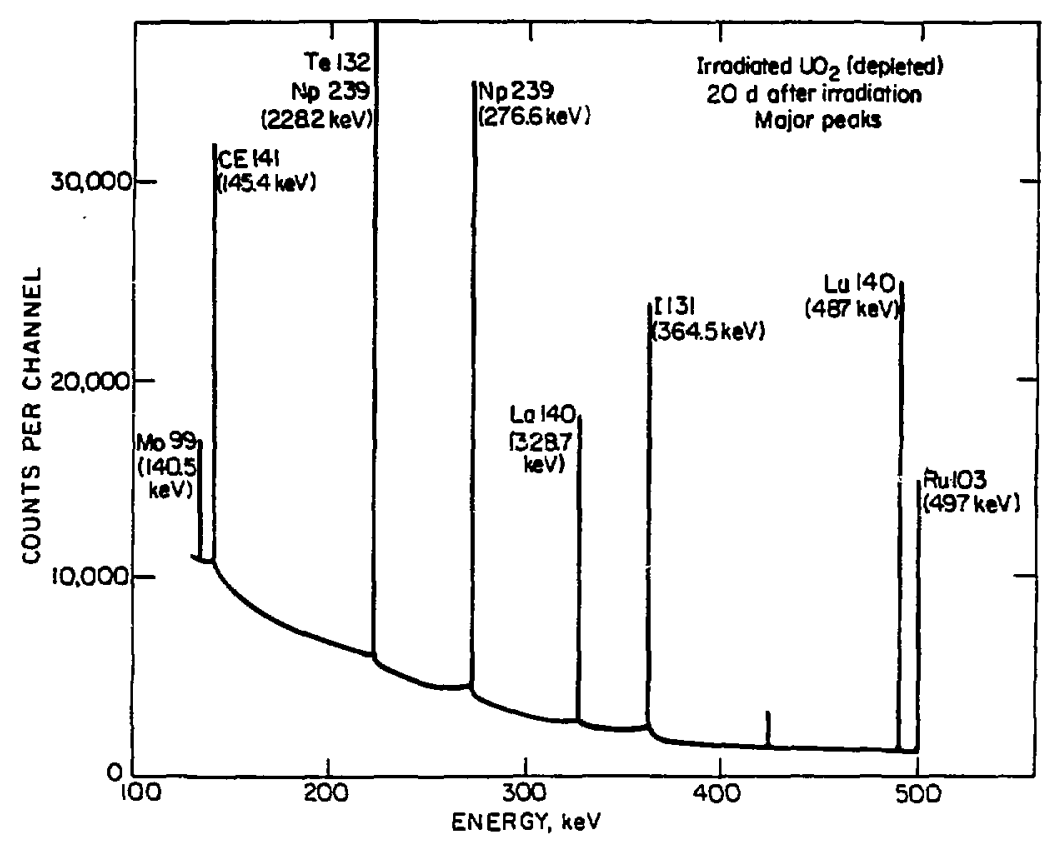

Fig. 4. Low-energy portion of the gama ray spectrum of lightlyirradiated $\mathrm{UO}_{2}$. 


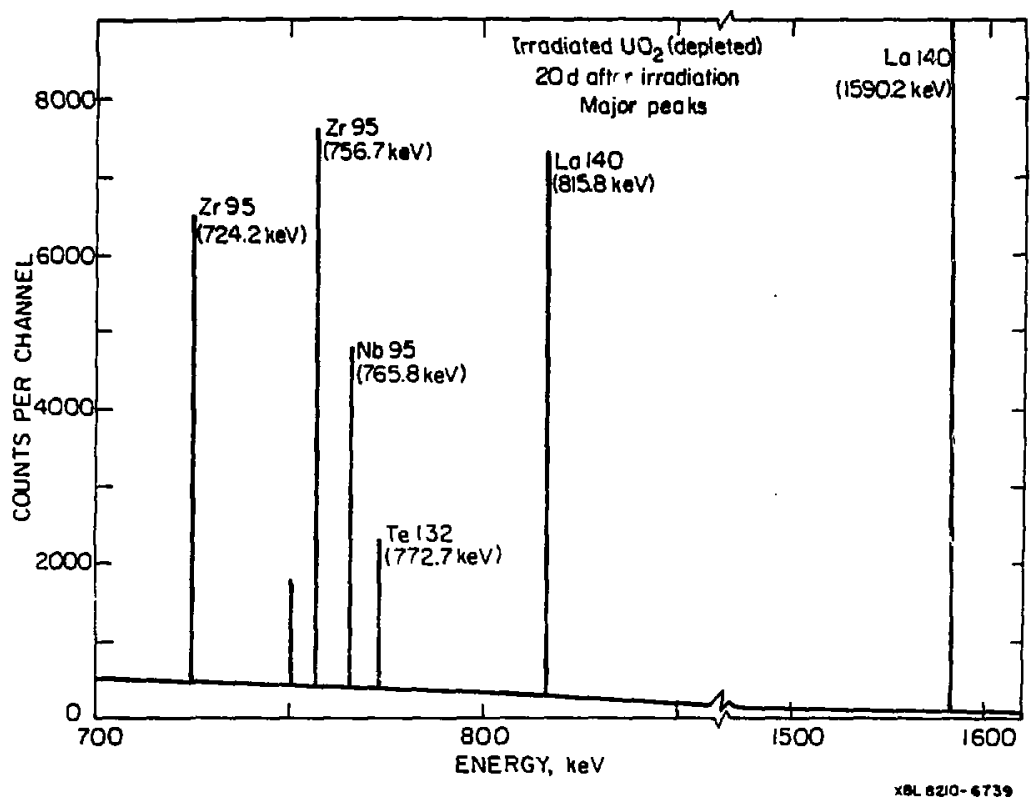

Fig. 5. High-energy portion of the gamme ray spectrum of lightlyirradiated $\mathrm{UO}_{2}$. 
Mass 131:

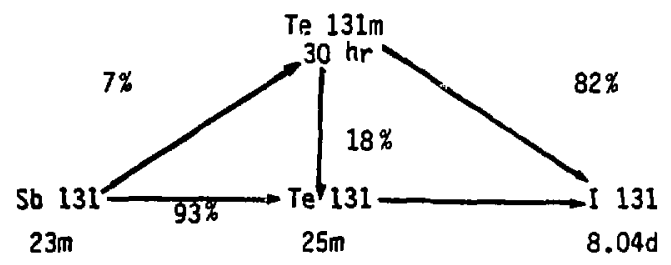

Eight days after irradiation, growth of I 131 from decay of Te $131 \mathrm{~m}$ is not significant. Therefore, I 131 can be used directly to study iodine diffusion.

Mass 132:

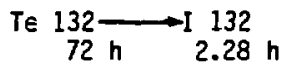

Precursors of Te 132 have negligibly short half lives. If counting is performed $\sim 12 \mathrm{~h}$ after an anneal, the $\mathrm{I} 132$ is in secular equilibrium with the remaining Te 132. Hence the difference in the activity of I 132 before and after annealing becomes a direct measure of the release of tellurium from the specimen.

\section{Mass 133:}

$$
\begin{aligned}
& 1 \mathrm{f} \\
& 20.9 \mathrm{~h}
\end{aligned}
$$

Eight days after irradiation, all precursors of I 133 have jecayed and the contribution of this nuclide to the growth of Xe 133 will not be significant. Measurement of the $81 \mathrm{keV}$ transition from Xe 133 decay will be a direct measure of xenon in the specimen.

Mass 140:

$$
\begin{gathered}
\mathrm{Ba} 140 \longrightarrow \mathrm{da} 140 \\
12.79 \mathrm{~d}
\end{gathered}
$$


Ba and La, which are less volatile fission products than I, Te and $X e$, are not expected to escape from the sample in this range of temperature. Therefore, lines due to $B a 140$ or La 140 decay have been used as reference 1 ines. Ten days after irradiation La 140 will be in secular equilibrium with $B a 140$ and then both La 140 and Ba 140 may be used for this purpose.

\section{Fractional Release Evaluation}

An anneal was performed with two irradiated samples and an unirradiated sample between them. As this experiment demonstrated that once released, no fission products return to the specimen, the fractional release is one minus the fraction retained:

$$
f=1-R
$$

$$
\begin{aligned}
& f=\text { fractional release } \\
& R=\text { fraction retained in the sample }
\end{aligned}
$$

$R$ may be determined by using two methods:

\section{a. Direct measurement.}

$R$ is the ratio of the fission product peak of interest after annealing to that before annealing divided by an experimentaliy-determined correction coefficient (COR) and corrected for decay. COR includes the effect of the nonuniform and asymmetric distribution of fission products produced by fission (see Appendix) 


$$
R=\frac{S_{a}}{S_{b}} \times \exp (-.693 \times t / P) \times \frac{1}{C O R}
$$

$S_{a}=$ net count under the peak of interest after annealing.

$S_{b}=$ net count under the peak of interest before annealing.

$t=$ time between the two countings.

$P=$ half-life of the nuclide.

COR = correction coefficient.

b. Relative measurement.

$R$ is the ratio of the fission product peak of interest for the sample to that of the standard after annealing, divided by COR. In this case, the correction coefficient includes the effect of the asymmetric, nonuniform distribution and the thickness difference between sample and standard (see Appendix).

$$
R=\frac{S_{1}}{S_{2}} \times \exp ( \pm .693 \times t / P) \times \frac{1}{\operatorname{COR}}
$$

$S_{1}=$ net count under the peak of interest for the sample efter annealing.

$S_{2}=$ net count under the peak of interest for the standard.

$t=$ time between the two countings.

$P=$ half-life of the nuclide.

* : + when sample is counted after standard.

- when sample is counted before standard.

COR $=$ correction coefficient.

Associated errors on these ratios are estimated in the Appendix. 
IV. RESULTS

Sample characteristics are given in Table 2. Thicknesses and weights have been measured, irradiation times reported and the number of fissions computed from Eq. (1).

In Table 3 results from eight anneals are reported. Anneal II was performed under partial vacuum. The results demonstrated that even with the oxygen getter action of the zirconium chips, samples were oxidized (they were reddish at the end of the anneals). The same observation applies to anneal VI. As shown by Lawrence [1] stoichiometry is a very influential parameter, at least on the xenon release rate. Therefore results from anneals II and VI should be used with care. Neither can results from anneal IV be trusted since a jump to $1650^{\circ} \mathrm{C}$ occurred during the first two minutes of the experiment. At $1500^{\circ} \mathrm{C}$ only anneals III and $V$ are considered acceptable. 
Table 2: Sample characteristics.

\begin{tabular}{|c|c|c|c|c|c|}
\hline $\begin{array}{l}\text { Sample* } \\
\text { Number }\end{array}$ & $\begin{array}{c}\text { Thickness } \\
\operatorname{mm} \pm .1\end{array}$ & $\begin{array}{l}\text { Height } \\
m g \pm .2\end{array}$ & $\begin{array}{l}\text { Irradiation } \\
\text { Time, min }\end{array}$ & $\begin{array}{c}\text { Number } \\
\text { of } \\
\text { Fissions } \\
\times 10^{-12}\end{array}$ & Utilization \\
\hline 25 & .69 & 459.4 & \multirow{2}{*}{18.0} & 5.0 & Anneal II , III \\
\hline 3 & .61 & 404.5 & & 4.4 & Anneal I \\
\hline 45 & .94 & 623.0 & \multirow{2}{*}{8.5} & 3.2 & \\
\hline 5 & .99 & 643.6 & & 3.3 & Anneal II, III, IV \\
\hline as & 1.00 & 671.5 & \multirow{2}{*}{12.0} & 4.8 & \\
\hline 7 & .98 & 648.7 & & 4.7 & Anneal IV, $V$ \\
\hline 85 & .89 & 594.7 & \multirow{2}{*}{13.0} & 4.6 & Anneal $y$ \\
\hline 9 & .94 & 621.4 & & 4.8 & Anneal III, IV \\
\hline 10 & 1.02 & 667.9 & \multicolumn{2}{|c|}{ no irradiation } & Anneal II \\
\hline 115 & .48 & 332.0 & \multirow{2}{*}{18.0} & 3.6 & \\
\hline 12 & .43 & 303.0 & & 3.3 & Anneal $V$ \\
\hline 135 & .94 & 624.6 & \multirow{2}{*}{12.0} & 4.5 & \\
\hline 14 & 1.07 & 708.2 & & 5.1 & Anneal VI \\
\hline $15 S$ & .84 & 561.8 & \multirow{3}{*}{13.0} & 4.4 & \\
\hline 16 & .84 & 565.0 & & 4.4 & Anneal VII \\
\hline $\mathrm{mI}$ & .91 & 322.0 & & 2.5 & \\
\hline 175 & .86 & 580.1 & \multirow{3}{*}{14.0} & 4.9 & \multirow{3}{*}{ Anneal VIII } \\
\hline 18 & .79 & 526.3 & & 4.4 & \\
\hline $\mathrm{m} 2$ & n.a. & 98.9 & & & \\
\hline
\end{tabular}

*S following sample number denotes a standard for the following sample; $\mathrm{ml}$ and $\mathrm{m} 2$ are single crystal specimens. 
Table 2, continued

Number

of

Sample* Thickness Weight Irradiation Fissions

Number $\mathrm{mm} \pm .1 \mathrm{mg} \pm .2$ Time, $\min \times 10^{-12}$ Utilization

\begin{tabular}{lll|lll}
\hline 195 & .58 & 394.4 & 20.0 & 4.6 & \\
20 & .56 & 376.5 & & & \\
$\mathrm{~m} 3$ & .61 & 193.8 \\
215 & .60 & 405.7 \\
22 & .45 & 302.5 & & 1.5 & \\
\hline
\end{tabular}

*S following sample number denotes a standard for the following sample; $m 3$ is a single crystal specimen. 
Tab1e 3: Experimental results.

\begin{tabular}{|c|c|c|c|c|c|c|c|}
\hline \multirow{2}{*}{$\begin{array}{l}\text { Anneal } \\
\text { Number }\end{array}$} & \multirow{2}{*}{$\begin{array}{l}\text { Anneal } \\
\text { Time } h r\end{array}$} & \multirow{2}{*}{$\begin{array}{c}\text { Temperature } \\
\text { "C }\end{array}$} & \multirow{2}{*}{$\begin{array}{l}\text { Samples } \\
\text { Annealed }\end{array}$} & \multicolumn{4}{|c|}{ Fractional Release of } \\
\hline & & & & I 131 & & 132 & $x \in 133$ \\
\hline \multirow[t]{2}{*}{$I^{a}$} & 1 & 1535 & 5 & $15.2 \pm 2.5$ & 16.2 & \pm 2.5 & $12.2 \pm 2.5$ \\
\hline & & & 2 & $14.0 \pm 2.0$ & 20.0 & \pm 2.0 & $12.0 \pm 3.0$ \\
\hline \multirow[t]{3}{*}{ I I I } & 1 & 1530 & 5 & $19.5 \pm 3.5$ & n.a. & & $14.0 \pm 4.5$ \\
\hline & & & 2 & $17.5 \pm 3.5$ & n.a. & & n.a. \\
\hline & & & 9 & $2.0 \pm 1.0$ & 7.5 & \pm 1.0 & $1.5 \pm 1.5$ \\
\hline \multirow[t]{2}{*}{$I V^{b}$} & 2 & 1535 & 7 & $9.0 \pm 1.0$ & 14.0 & \pm 3.5 & $3.9 \pm 1.0$ \\
\hline & & & 9 & $11.7 \pm 1.0$ & 27.5 & \pm 3.5 & n.a. \\
\hline \multirow[t]{3}{*}{$v$} & 2 & 1530 & 7 & $14.6 \pm 1.0$ & 15.0 & \pm 1.0 & $4.0 \pm 1.0$ \\
\hline & & & 12 & $4.0 \pm 1.0$ & 10.25 & $\neq 1.0$ & $4.0 \pm 2.0$ \\
\hline & & & 8 & $4.0 \pm 1.0$ & n.a. & & n.a. \\
\hline$V I^{c}$ & 9 & 1450 & 14 & $18.0 \pm 3.0$ & 21.2 & \pm 2.0 & $20.0 \pm 2.0$ \\
\hline \multirow[t]{2}{*}{ VII } & I & 1630 & 16 & $8.0 \pm 0.4$ & 22.0 & \pm 2.0 & n.a. \\
\hline & & & $\mathrm{ml}$ & $1.0 \pm 1.0$ & 2.25 & \pm 1.65 & n.a. \\
\hline \multirow[t]{2}{*}{ VIII } & 1 & 1700 & 18 & & & & \\
\hline & & & $\mathrm{m} 2$ & n.a. & $\cdots$. & & n.a. \\
\hline IX & 7.3 & 1450 & 20 & $5.5 \pm 1.0$ & 9.5 & \pm 1.0 & $3.0 \pm 2.0$ \\
\hline \multirow[t]{2}{*}{$\dot{x}$} & 1.5 & $1650^{d}$ & 22 & $7.4 \pm 1.5$ & 18.4 & \pm 1.4 & n.a. \\
\hline & & & $\mathrm{m} 3$ & $0.6 \neq 0.5$ & 2.8 & \pm 0.8 & n.a. \\
\hline
\end{tabular}

a: Anneal performed under partial vacuum; samples were reddish after heating.

b: A jump to $1650^{\circ} \mathrm{C}$ occurred during the first two minutes of the anneal.

c: Samples were reddish at the end of the anneal; probably oxidized.

d: Thermocouple changed; calibration curve of Fig. 3 cannot be used. 


\section{DISCUSSION OF RESULTS}

\section{The Equivalent Sphere Model}

Fission product gases are released by a combination of mechanisms:

- diffusion in the lattice to grain boundaries.

- diffusion through the grain boundaries or other channels leading to open surfaces.

Booth [6] postulated that xenon migration in sintered $\mathrm{UO}_{2}$ could be modeled as an assembly of spheres communicating with the atmosphere through such channels. The radius of the equivalent sphere is denoted by " $\mathrm{a}$ ". In polycrystalline specimens the equivalent radius does not correspond to any physical dimension characterizing the specimen. It is smaller than the gross dimension (i.e., the half-thickness of the wafer used in the present test) but larger than the grain size. Only in the case of single crystals does diffusion occur to the external surface of the solid.

By using Ficks law:

$$
\frac{\partial C}{\partial t}=0 \frac{1}{r^{2}} \frac{\partial}{\partial r}\left(r^{2} \frac{\partial C}{\partial r}\right)
$$

and the initial boundary conditions:

$$
\begin{aligned}
& C(r, 0)=C_{0} \\
& C(a, t)=0 \\
& C=\text { fission product concentration } \\
& D=\text { effective diffusion coefficient. }
\end{aligned}
$$

The fractional release can be expressed by [7]: 


$$
f=\frac{6}{\sqrt{\pi}} \sqrt{\frac{D t}{a^{2}}}-3\left(\frac{D t}{a^{2}}\right)
$$

where $f$ is the fractional release expressed by

$$
f=\frac{\int_{0}^{a} 4 \pi r^{2} c(r, t) d r}{\frac{4}{3} \pi a^{3} C_{0}}
$$

Solving (5) for $\frac{0}{a^{2}}$ :

$$
\frac{0}{a^{2}}=\frac{\left[1-\sqrt{1-f \frac{\pi}{3}}\right]^{2}}{\pi t}
$$

In its simplest form, the equivalent sphere model implies that over dimensions large compared to the grain radius, the concentration gradient of the diffusing species is constant. Hence, for large enough samples with uniform initial concentrations of the diffusing species, annealing would yield a uniform decrease in concentration through the sample, as opposed to the large gradients expected for diffusion in single crystals. More realistically, so long as the transport of the diffusing species through grain boundaries is sufficiently unimpeded, concentration gradients would be small compared to those obtained with single crystals.

For the present experiments where gamma ray measurements are performed to define fractional releases, uniform sampling of the emission from all segments of the specimens is perturbed by attenuation due to the high $Z$ of uranium. For the $773 \mathrm{keV}$ line from decay of I $132 \mathrm{~m}$ this is negligible and for the $364 \mathrm{keV}$ line from I 131 the attenuation 
is small enough to permit a fairly uniform sampling of the specimens. However, for the $81 \mathrm{keV}$ line from Xe 133 decay, the mean free path in the $\mathrm{UO}_{2}$ corresponds to $10-20 \%$ of the thickness of the specimens and hence a large bias in favor of concentration changes at the surface is inherent in a direct application of the counting data.

In the present experiments, no measurements of the concentration profiles of the volatile species remaining in the samples after anneal nave been performed. The ratios of gamma ray intensities before and after anneal have been used directly to examine the extent to which release follows a diffusion model and to derive values for diffusion parameters of each species. This is equivalent to the interpretation of the data in terms of the equivalent sphere model. While the bias introduced for tellurium and iodine will not be severe, the neglect of concentration gradients will result in overestimates of the release fractions for xenon, which translates into deduced diffusion coefficients that are too large.

The effective diffusion coefficient $D / a^{2}$ may be computed from Eq. (6) by using the fractional release data given in Table 3. Results obtained for $D / \mathrm{a}^{2}$ for all acceptable anneals are listed in Table 4 .

\section{Square-root-of-t Law}

For small fractional release ( $f<20 \%$ corresponding to short annealing time, i.e.,

$$
\frac{D t}{a^{2}} \ll 1
$$


Table 4: Effective diffusion coefficients.

\begin{tabular}{|c|c|c|c|c|}
\hline \multirow{2}{*}{$\begin{array}{l}\text { Anneal } \\
\text { Number }\end{array}$} & \multirow{2}{*}{$\begin{array}{l}\text { Samp le } \\
\text { Number }\end{array}$} & \multicolumn{3}{|c|}{$0 / a^{2} \times 10^{9}, s^{-1}$} \\
\hline & & I 131 & Te 132 & $x e 133$ \\
\hline III/V & $9 / 8 / 12$ & $(1.1-2.2)$ & $11-17$ & $0.5-2.2$ \\
\hline VII & 16 & $14-18$ & $110-160$ & n.a. \\
\hline VIII & 18 & $140-180$ & $850-1000$ & $21-44$ \\
\hline$I X$ & 20 & $0.6-1.2$ & $2.5-3.9$ & $0.03-0.2$ \\
\hline
\end{tabular}


the last term of Eq. (5) may be neglected and the fractional release expressed as:

$$
f=\frac{6}{\sqrt{\pi}}\left(\frac{D t}{a^{2}}\right)^{1 / 2}
$$

The fractional releases of I 131 and Te 132 during anneals $I I I$ and $\checkmark$ from samples 9,12 and 8 were used to test this prediction (Table 5). 
Table 5: Test of square-root-of-t law

\begin{tabular}{cccc}
\hline Sample No. $\begin{array}{c}\text { Anneal } \\
\text { time } \\
\text { in hrs }\end{array}$ & $f / \sqrt{t}$ & $\left(h^{-1 / 2}\right)$ \\
\hline 9 & 1 & $2.0 \pm 1$. & $7.5 \pm 1$. \\
12 & 2 & $2.8 \pm .7$ & $7.3 \pm .7$ \\
8 & 2 & $2.8 \pm .7$ & NA \\
\hline
\end{tabular}

Within the large uncertainties, the data are consistent with diffusion model predictions. Due to the small release fractions, useful data was not determined for Xe 133.

3. Temperature Dependence of the Diffusion Coefficient

Table 4 gives $0 / \mathrm{a}^{2}$ for different temperatures. These data are plotted in Arrhenius fashion in Fig. 6.

Classical diffusion coefficients are known to have the following temperature dependence:

$$
\begin{aligned}
& O=D_{0} \exp (-Q / R T) \\
& Q=\text { activation energy in } \mathrm{kcal} / \mathrm{mole} \\
& R=\text { universal gas constant }=1.987 \mathrm{cal} / \mathrm{mole} \mathrm{K}
\end{aligned}
$$

It appears from fig. 6 that the effective diffusion coefficient has the same behavior as the classical diffusion coefficient. The activation energies derived from these data are: 


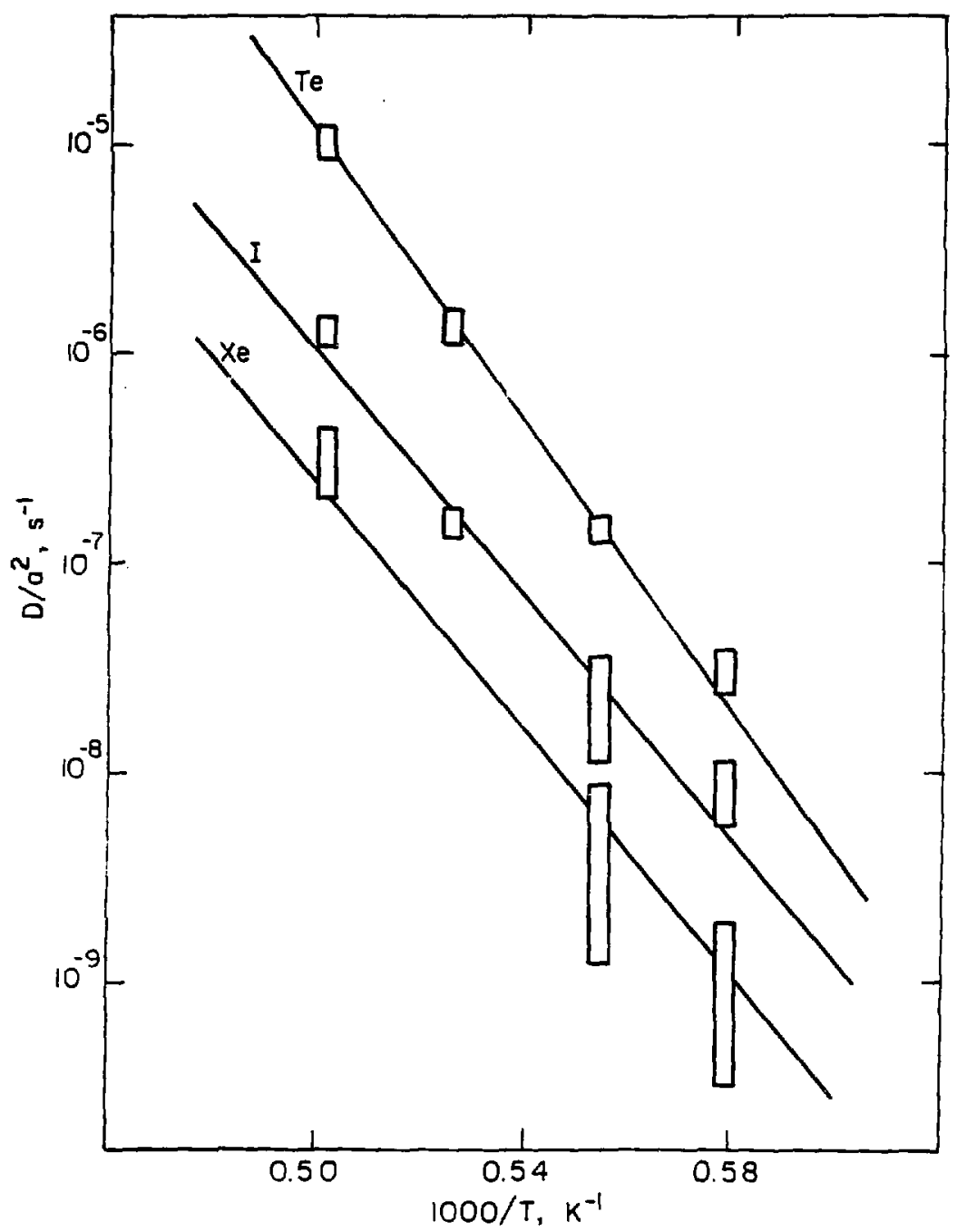

XELO2!J- 6742

Fig. 6. Effective diffusion coefficients of iodine, tellurium and xenon in lightly-irradiated $\mathrm{UO}_{2}$. 


$$
\begin{array}{ll}
\text { For I } 131 & Q_{I}=140 \pm 10 \mathrm{kcal} / \mathrm{mole} \\
\text { For Te } 132 & Q_{T e}=155 \pm 25 \mathrm{kcal} / \mathrm{mole} \\
\text { For Xe } 133 & Q_{X e}=140 \pm 40 \mathrm{kcal} / \mathrm{mole}
\end{array}
$$

According to Lawrence [1], the activation energy for xenon diffusion in $\mathrm{UO}_{2}$ varies from $36 \mathrm{kcal} / \mathrm{mole}$ to $140 \mathrm{kcal} / \mathrm{mole}$ as the stoichiometry is decreased from 2.12 to 2.00 . Thus the release rate of xenon is a good indicator of excessive sample oxidation.

Turnbull [2] found an activation energy of $35 \mathrm{kcal} / \mathrm{mole}$ for iodine diffusion and $30 \mathrm{kcal} / \mathrm{mole}$ for xenon diffusion. Such a low activation energy for xenon diffusion indicates, according to Lawrence, that the $\mathrm{UO}_{2}$ used was oxidized. As it has been proved in this study that the stoichiometry strongly influenced the release of iodine as well, a comparison with Turnbull results is difficult.

\section{Equivalent Sphere Radius}

To determine the effective diffusion coefficient from results given above, the equivalent radius must be measured.

A simple method to estimate the radius of the equivalent sphere is to anneal a single crystal at the same time as a polycrystal and compare the releases from the two samples. In general, the short-time fractional release from a body of arbitrary surface-to-volume ratio $(s / v)$ is

$$
f=\frac{2}{\sqrt{\pi}} \frac{5}{v} \sqrt{D t}
$$


For an equivalent sphere of radius $a, s / v=3 / a$. For a single crystal disk of thickness $L, s / v=2 / L$. The equivalent sphere radius is then given by:

$$
a=\frac{3}{2} \frac{f_{s}}{f_{p}} L
$$

$f_{S}=$ fractional release from the single crystal

$f_{p}=$ fractional release from the polycrystal

$L=$ thickness of the single crystal (Table 2)

Using the data from Table 3 for anneals VII and $x$, Table 6 shows the equivalent sphere radius for $I$ and $T e$ at $-1650^{\circ} \mathrm{C}$.

Table 6: Equivalent sphere radii.

\begin{tabular}{ccc}
\hline Anneal No. & \multicolumn{2}{c}{ a in um } \\
\hline & 1131 & Te 132 \\
VII & $190 \pm 100$ & $150 \pm 60$ \\
$X$ & $120 \pm 120$ & $230 \pm 100$ \\
\hline
\end{tabular}

Although the equivalent sphere radius is not identical to the grain size, these two quantities are related [2]. Sintered $\mathrm{UO}_{2}$ usually has a grain size of $d_{0}=5$ um. Growth of the grains may be derived from Fig. 14-13(b) and Eq. (14.47) from Ref. 7: 


$$
\begin{array}{r}
\text { After I hr. at } 1450^{\circ} \mathrm{c}, \frac{d-d_{0}}{d_{0}}=0.2 \% \\
1500^{\circ} \mathrm{c}, \frac{d-d_{0}}{d_{0}}=0.5 \% \\
1600^{\circ} \mathrm{c}, \frac{d-d_{0}}{d_{0}}=2.0 \% \\
1700^{\circ} \mathrm{c}, \frac{d-d_{0}}{d_{0}}=18.0 \% \\
1750^{\circ} \mathrm{c}, \frac{d-d_{0}}{d_{0}}=30.0 \%
\end{array}
$$

Since the samples were reduced for $2-3 \mathrm{hrs}$, at $1750^{\circ} \mathrm{C}$ prior to irradiation, grain sizes during the anneals are probably of the order of $10 \mu \mathrm{m}$. As the temperatures of the anneals were below $1750^{\circ} \mathrm{C}$, grain growth may be neglected.

For polycrystalline specimens with an average grain size of $10 \mathrm{\mu m}$, Turnbull [2] found an equivalent sphere radius of $60 \mu \mathrm{m}$ for a lightly irradiated sample. This is $-1 / 4$ to $1 / 2$ of the values in Table 6 .

Using results from Tables 5 and 6 , diffusion coefficients at $1400^{\circ} \mathrm{C}$ can be evaluated by interpolation

$$
\begin{array}{ll}
\text { for I } 131 \quad 0_{1400}=(6 \pm 4) \times 10^{-17} \mathrm{~m}^{2} / \mathrm{s} \\
\text { for Te } 132 D_{1400}=(1.7 \pm 0.7) \times 10^{-16} \mathrm{~m}^{2} / \mathrm{s} \\
\text { for Xe } 1330_{1400}=(1.1 \pm 1) \times 10^{-17} \mathrm{~m}^{2} / \mathrm{s}
\end{array}
$$

As discussed in the introduction, comparing these results with previous measurements is difficult. Considering the data reviewed by Lawrence [1], no single experiment of a comparable nature appears to 
be included. As a result, the best that can be done appears to be a comparison with Lawrence's evaluation of data taken in post-irradiation anneal experiments on sintered and fused $\mathrm{UO}_{2}$ samples. Treating these data statistically (after correction for the correlations found with burnup and stoichiometry), Lawrence reports an average value for $D_{X e}(1400)$ of $5.5 \times 10^{-19} \mathrm{~m}^{2} / \mathrm{s}$ with one sigma limits of $5.4 \times 10^{-20}$ and $5.6 \times 10^{-18} \mathrm{~m}^{2} / \mathrm{s}$, respectively (see $\mathrm{Fig} .7$ ). The result obtained from the present experiment lies at the upper limit of this range within errors. However, the value $D_{X e}(1400)$ determined in this study is in good agreement with the value from the recommended data set reviewed by Matzke [8].

For iodine, much less experimental data is available. The in-core experiments of Friskney and Turnbull [2] seem well documented and after correction for the difference in equivalent sphere radius between their work and the present experiments, one derives a diffusion constant of about $3.8 \pm 3.3 \times 10^{-20} \mathrm{~m}^{2} / \mathrm{s}$ at $1400^{\circ} \mathrm{C}$. Although the mean values suggest the present result is a factor of about 1500 larger, such a comparison is highly misleading due to the large uncertainties which allow the ratio of the two values to be compietely uncertain.

The diffusion constant for tellurium is the first reported to our knowledge. 
33

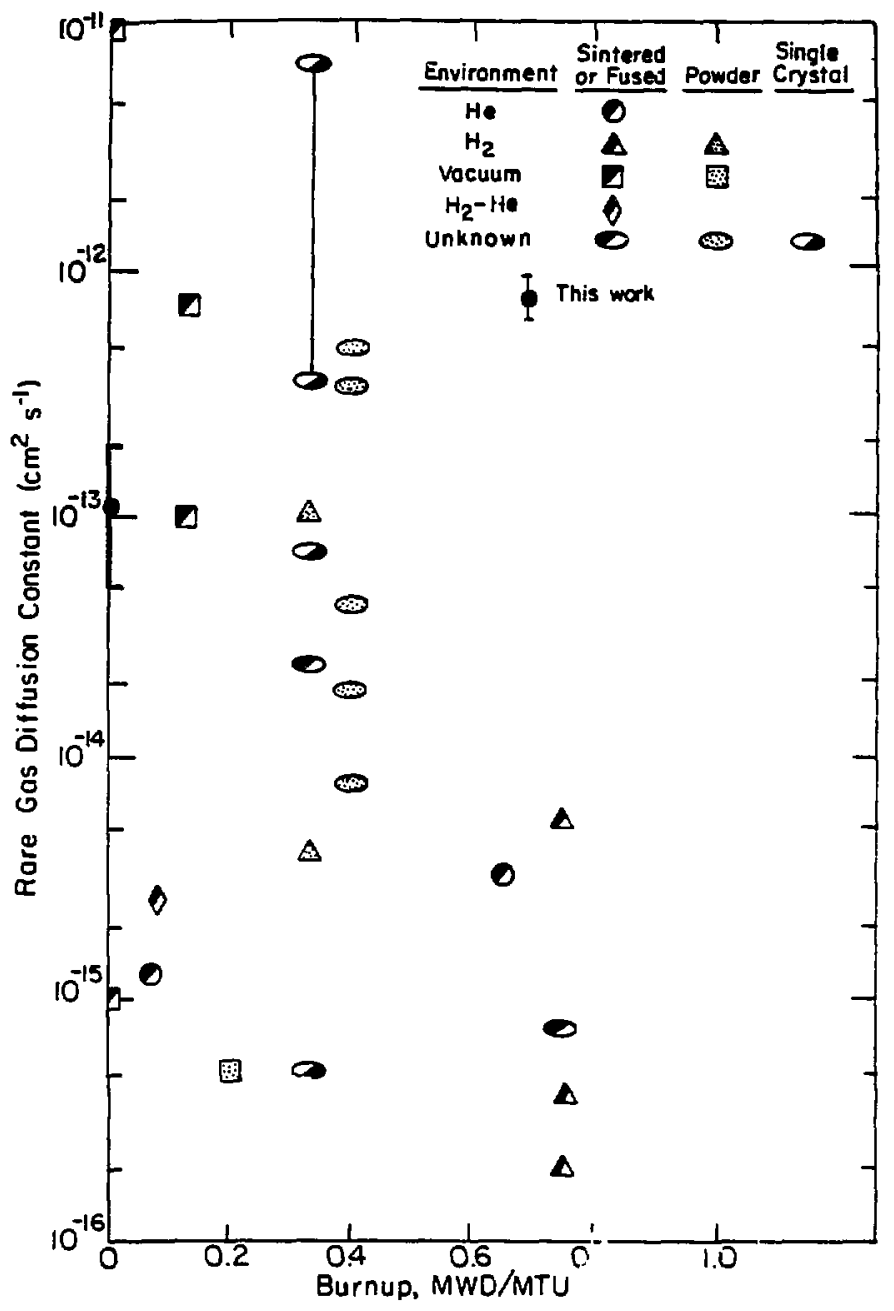

X BL $832-5272$

Fig. 7. Diffusion coefficient of xenon in $\mathrm{NO}_{2}$ at $1400^{\circ} \mathrm{C}$. References for the various experiments sumarized here are given by Larrence [1]. 
VI. CONCLUSION

1. An experimental method to measure releases of I 131, Te 132, Xe 133 from lightly irradiated $\mathrm{UO}_{2}$ samples had been developed. It can provide accuracies of about $\pm 1 \%$ in fractional releases of I and Te.

2. The equivalent sphere model appears to be adequate to describe release kinetics. The results are not in agreement with the iodine release model proposed by Malen [9] in which iodine release occurs only as a result of moving grain bsundaries.

3. Release of $x e 133$ and I 131 are very sensitive to stoichiometry. The result for xenon release is constant with previous findings.

4. By using single crystal specimens, effective diffusion coefficients and activation energies for I 131, Te 132 and Xe 133 have been found. Although comparison with literature results is difficult, the diffusion coefficients found here tend to be larger than the average values reported.

5. Of principal importance is the result that the release rates both $I$ and $\mathrm{Te}$ from $\mathrm{UO}_{2}$ appear higher than for xenon over the temperature range $1400^{\circ}-1700^{\circ} \mathrm{C}$. 
APPENDIX: FRACTIONAL RELEASE EVALUATION AND ASSOCIATEO ERRORS

\section{Peak Areas Determination and Statistic Errors}

Background ur,der each peak was evaluated by applying a linear approximation between the mean count numbers before and after the peak.

Peaks areas were evaluated by summing all channel counts that were significantly higher t!lan background in the vicinity of the peak.

Error calculation on the peak areas were performed as follows:

$N=$ total counts under the peak

$B=$ total background counts under the peak

$S=$ net counts of the peak $(S=N-B)$

Then standard deviacisir ar $S, \sigma_{S}$, is given by the error propagation theorem.

$$
\begin{aligned}
& \sigma_{s}^{2}=\sigma_{n}^{2}+\sigma_{B}^{2} \\
& \sigma_{s}=(N+B)^{1 / 2}=(2 N-S)^{1 / 2}
\end{aligned}
$$

2. Correction Coefficient Determination (COR) and Errors

It appears very quickly that a correction coefficient (COR) should be introduced to correct for different changes in parameters when either the direct method or the relative method are used.

a. Non-uniform distribution of fission product. In these irradiations, sample and standard were placed next to each other. Therefore, for thick specimens (thickness $\geq 1 \mathrm{~mm}$ ), flux depression occurred during irradiation (due to $U 238$ absorption). The assumption of uniform fission product distribution is no longer acceptable.

After a thick irradiated sample was counted from one side, it was reversed, exposing the other side to the detector, and counted for the 
same time. After correction for decay, ratio of the peaks was computed. Figure 8 displays the results for sample No. 8. The solid line is an interpolated curve between the data. This curve demonstrates that the distribution of fission product is nonuniform and asymmetric for thick samples. This does not alter results on fission product release, but complicates data analysis.

If accurate results are needed, the two sides of a sample shouid be distinguished or the flux depression reduced by use of thinner specimens.

b. Differences between standard and sample. Standard and sample do not have aiways the same thickness. A correction for thickness difference must be introduced in the evaluation of the fractional release. As the attenuation of $\mathrm{y}$-rays in $\mathrm{UO}_{2}$ depends on the energy, this correction depends also on the energy of the y-ray observed. Ref. 10 gives half thicknesses $\left(d_{1 / 2}\right)$ for different energies.

$$
\begin{array}{ll}
\text { for } 81 \mathrm{keV} \text { (Xe 133) } & d_{1 / 2}=0.02 \mathrm{~cm} \\
\text { for } 364 \mathrm{keV} \text { (I 131) } & d_{1 / 2}=0.2 \mathrm{~cm}
\end{array}
$$

The ratio of the height of a pezk of the sample to that of the standard before annealing may be expressed, assuming a uniform distribution of fission products, as:

$$
R=\frac{\int_{0}^{e_{1}} 2^{\left(-x / d_{1 / 2}\right)} d x}{\int_{0}^{e_{2}} 2^{\left(-x / d_{1 / 2}\right)} d x}
$$




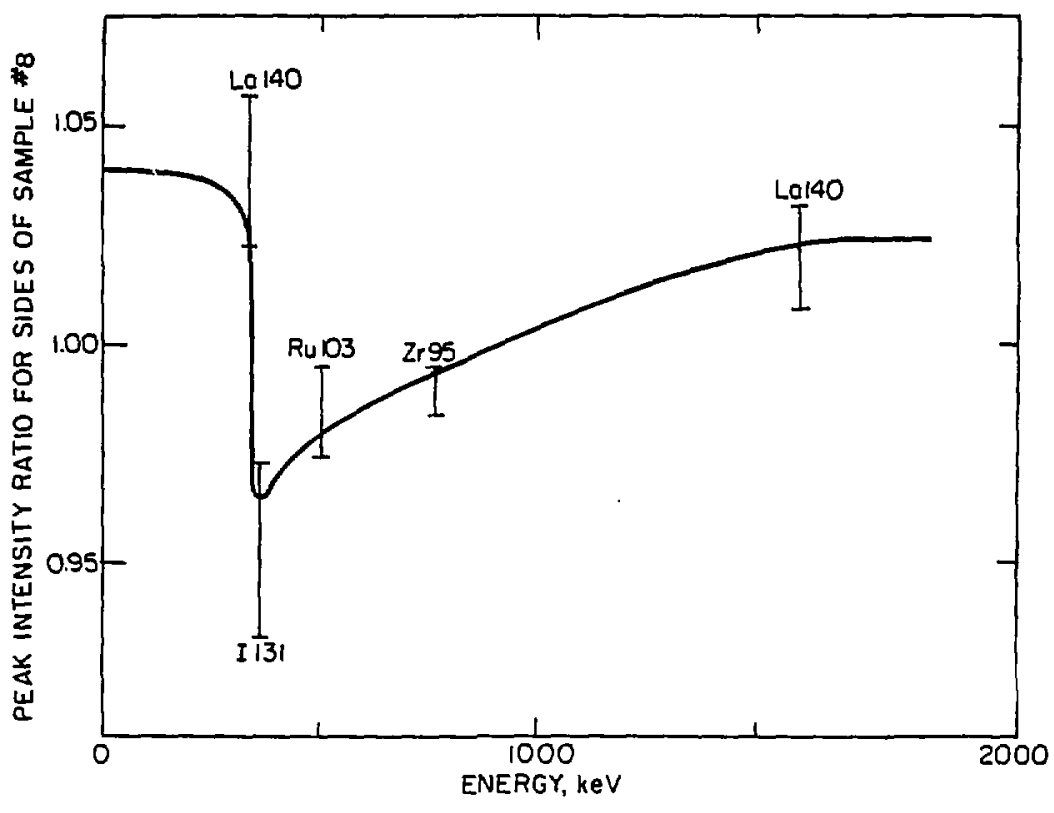

Fis. 8. Ratio of the intensities of various fission product gemma ray peaks measured from the two faces of a sample, one of which had been shielded during irradiation by another sample. 


$$
\begin{aligned}
& e_{1}=\text { thickness of the standard. } \\
& e_{2}=\text { thickness of the sample } \\
& R=\frac{1-\exp \left[-\log \left(2 e_{1} / d_{1 / 2}\right)\right]}{1-\exp \left[-\log _{2}\left(2 e_{2} / d / 1\right)\right]}
\end{aligned}
$$

The solid line in Fig. 9 is $R$ versus energy from Eq. (9) for $e_{1}=0.89 \mathrm{~mm}$ and $e_{2}=0.94 \mathrm{~mm}$.

The combination of these two effects (different thickness and non-uniform distribution) will not be deternined theoretically but rather pragmatically as follows:

c. Correction coefficient evaluation. As the two effects described above were often combined, correction coefficients have been evaluated each time by using the spectra themselves. Ratios of nonvolatile fission product peaks (e.g., La 140) have been computed for the two spectra considered. After plotting these ratios versus peak energies the correction coefficient (COR) may be easily interpolated for different energies. An example of such a calculation is given in section 4. Errors have been placed on these correction coefficients. These errors are of the order of the statistical error. 3. Fraction Retained (R) Evaluation ard Errors on $R$ If the direct method is used (see Sec. III.2):

Eq. (3): $R=\frac{S_{a}}{S_{b}} \times \exp (-.693 \times t / P) \times \frac{1}{C O R}$ 


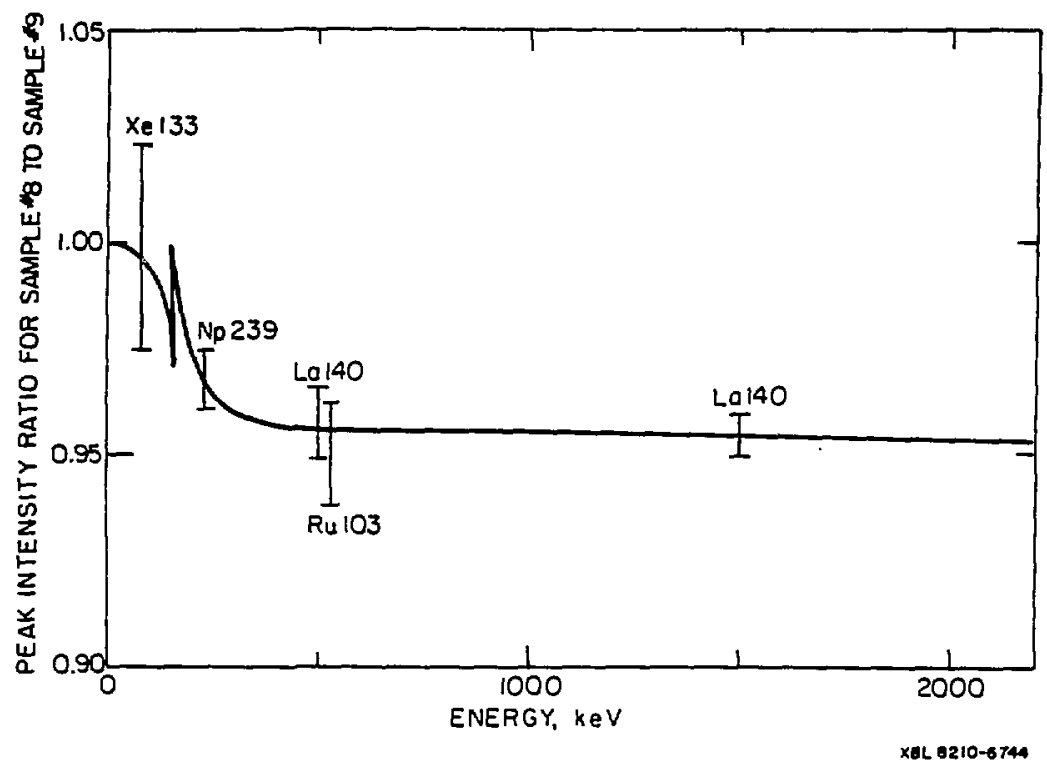

Fig. 9. Ratio of the intensities of fission product garma ray peaks from two wafers, one $0.89 \mathrm{~mm}$ thick and the other $0.94 \mathrm{~m}$ thicis. 
$\frac{d R}{R}=\left[\left(\frac{\sigma_{s}}{s_{a}}\right)^{2}+\left(\frac{\sigma_{b}}{s_{b}}\right)^{2}\right]^{1 / 2}+\frac{d[\exp (-.693 t / P)]}{d P}+\frac{d \operatorname{COR}}{C O R}$

$\frac{d R}{R}=\left[\left(\frac{\sigma_{s_{a}}}{s_{a}}\right)^{2}+\left(\frac{\sigma_{b}}{s_{b}}\right)^{2}\right]^{1 / 2}+\frac{.693 t}{p} \times \frac{d P}{p}+\frac{d \operatorname{COR}}{\operatorname{COR}}$

$\frac{d P}{P}$ may be evaluated from the data given in Ref. 10 . It is usually of the order of $5 \times 10^{-3}$.

If the relative method is used:

Eq. (4): $R=\frac{S_{1}}{S_{2}} \times \exp \pm(.693 \times t / P) \times \frac{1}{\operatorname{COR}}$

$$
\frac{d R}{R}=\left[\left(\frac{\sigma_{1} s_{1}}{s_{1}}\right)^{2}+\left(\frac{\sigma_{s_{2}}}{s_{2}}\right)^{2}\right]^{1 / 2}+\frac{d C O R}{C O R}+\frac{.693 t}{P} \times \frac{d P}{P}
$$

The error on the exponential term had been neglected for in this case $t \ll P$ and therefore $\frac{.693 t}{P} \times \frac{d P}{P}$ is negligible:

$$
\frac{d R}{R}=\left[\left(\frac{\sigma_{s_{1}}}{s_{1}}\right)^{2}+\left(\frac{\sigma_{s_{2}}}{s_{2}}\right)^{2}\right]^{1 / 2}+\frac{d C O R}{C O R}
$$

4. Practical Example of Fractional Release and Error Determination

In this section, release of I 131 from Sample No. 12 during anneal No. IV (2 hrs. under $\mathrm{H}_{2}$ ) is computed. Peak areas are given and 
results are called "Spectrum Analysis". Results with error calculation are denoted as "Data Interpretation." 
SPECTRUM ANALYSIS

SAMPLE No. 11 DATE: 9/13 9:05 COUNTED DURING: 8000s P05:09

\begin{tabular}{rrlrrr}
\hline CHAN & ENER. & ELEMENT & N & S & S/S \\
556 & 276.6 & Np239 & $1,012,680$ & 913,880 & .001 \\
667 & 329.7 & Np239 & 151,920 & 111,920 & .004 \\
736 & 364.5 & I131 & 151,329 & 104,070 & .005 \\
3291 & 1596.0 & La140 & 70,320 & 69,130 & .004 \\
\hline
\end{tabular}

SAMPLE NO. 12 OATE: 9/13 12:05 COUNTED DURING: 8000s P0S:09

\begin{tabular}{rrlrrrr}
\hline CHAN & ENER. & ELEMENT & N & S & 5/S & RATIO \\
556 & 276.6 & Np239 & 927,600 & 851,700 & .001 & .967 \\
667 & 329.7 & Np239 & 138,280 & 102,280 & .004 & .948 \\
736 & 364.5 & I131 & 130,140 & 91,570 & .005 & .891 \\
3291 & 1595.0 & LaI40 & 63,430 & 52,430 & .004 & .909 \\
\hline
\end{tabular}

$$
\begin{aligned}
& N=\text { total counts } \\
& S=\text { net counts }
\end{aligned}
$$

RATIO: ratios of peak areas for sample (No. 12) and standard (No. 11) after correction for decay.

For I 131 COR $=.925 \pm 0.01$ (by interpolation using the two Np 239 peaks and the La 140 peak) 


\section{SPECTRUM ANALYSIS}

SAMPLE NO. 12 DATE: $9 / 9$ 10:20 COUNTED DURING: 8000s P0S:25

\begin{tabular}{rrlrrr}
\hline \hline CHAN & ENER. & ELENT & N & \multicolumn{1}{c}{$S$} & S/S \\
556 & 276.6 & Np239 & 966,200 & 886,270 & .001 \\
660 & 328.7 & La140 & 43,320 & 18,060 & .015 \\
736 & 364.5 & I131 & 68,080 & 42,544 & .008 \\
3291 & 1596.0 & Lal40 & 23,930 & 23,420 & .007 \\
\hline
\end{tabular}

SAMPLE NO. 12 DATE: $9 / 10$ 12:10 COUNTED DURING: $8000 \mathrm{~s}$ POS:25

\begin{tabular}{|c|c|c|c|c|c|c|}
\hline $\begin{array}{r}\text { CHAN } \\
556 \\
660 \\
736 \\
3291\end{array}$ & $\begin{array}{r}\text { ENER. } \\
276.6 \\
328.7 \\
364.5 \\
1596.0\end{array}$ & $\begin{array}{l}\text { ELENT } \\
\text { Np239 } \\
\text { La140 } \\
\text { I13i } \\
\text { La140 }\end{array}$ & $\begin{array}{r}N \\
760,200 \\
37,610 \\
57,700 \\
23,340\end{array}$ & $\begin{array}{r}5 \\
647,906 \\
17,495 \\
37,563 \\
22,890\end{array}$ & $\begin{array}{l}s / 5 \\
.002 \\
.014 \\
.008 \\
.007\end{array}$ & $\begin{array}{l}\text { RATIO } \\
1.004 \\
1.027 \\
1.037 \\
1.036\end{array}$ \\
\hline
\end{tabular}

$N=$ total counts

$S=$ net counts

RATIO = ratio of peak areas for sample No. 12 before and after heating after correction for decay

For I $131 \mathrm{COR}=1.01 \pm .01$ 


\section{DATA INTERPRETATION FOR I 131 SAMPLE NO. 12 ANNEAL V}

\section{RELATIVE METHOD}

SAMPLE No. 11 DATE: 9/13 9:05

SAMPLE No. 12 DATE: $9 / 13$ 12:05

TIME DIFFERENCE: $\quad 3.0 \mathrm{~h}$

$$
\begin{aligned}
& s_{11}=104,070 \\
& s_{12}=91,570 \longrightarrow \text { (decay correction) } s_{12}=92,744
\end{aligned}
$$

$R=\left(S_{12} / S_{11}\right) / C O R=.891 / .926=.962 d R / R=.005^{2}+.005^{2}+.02=.0 \hat{c} 7$

$$
.949>R>.975
$$

DIRECT METHOD

SAMPLE No. 12 DATE: $9 / 10 \quad 12: 10$

SAMPLE No. 12 DATE: $9 / 9 \quad 10: 20$

TIME DIFFERENCE: $\quad 25.8 \mathrm{~h}$

BEFORE: $\quad S B=42,544$

AFTER: $\quad S A=37,563 \longrightarrow$ (decay correction) $S A=41,205$

$R=(S A / S B) / C O R=.969 / 1.01=.9594 \quad d R / R=.008^{2}+.008^{2}+.003+.02=.034$ 
5. Improvements in the Experimental Method

a. Asymetric fission product distribution. The most difficult problem encountered was the asymmetric fission product distribution. This difficulty may be eliminated by:

- irradiating sample and standard with a very large gap. As the neutron mean free path in the reactor was $2.5 \mathrm{~cm}$, at least a $5 \mathrm{~cm}$ gap is necessary to achieve a symmetrical distribution. This method was tested satisfactorily with samples No. 19, 20, 21, and 22 .

- counting one side for the half of the counting period then reversing the specimen and counting the other side for the other half.

- choosing thinner samples in order to reduce the flux depression. However practical thicknesses of the samples are limited by the cutting machine and the specimen brittleness during handling. A thickness of $0.5 \mathrm{~mm}$ is the 1 imit for this kind of experiment.

b. r-ray absorption. The thinner the sample, the smaller is the attenuation of $\gamma$-rays and the better are the statistics. This remark is specially true for low energy peaks such as the $81 \mathrm{keV} \mathrm{Xe} 133$ Y ray.

c. Heating time. The relative error on the fractional release may be dramaticaliy reduced by increasing the heating period. This also reduces the error due to ramping the temperature. From practical considerations, heating times are limited to $12 \mathrm{hr}$ as no automatic control of temperature was available. 


\section{REFERENCES}

1. G. T. Lawrence, J. Nucl. Mater., 71 (1978) 195.

2. C. A. Friskney, J. A. Turnbul1, J. Nucl. Mater., 79 (1979) 184.

3. M. Peehs and G. Kaspar, High Temp.-High Press., to be published.

4. K. C. Kim, "Oxygen Diffusion in Hyperstoichiometric $\mathrm{UO}_{2}$, " Ph.D. thes is, LBL-11905 (1981).

5. M. A. Wakat, Nuclear Data Tables $\underline{8}, 445-666$ (1971).

6. A. H. Booth, AECL (Canada) Report D.C.I-27 (1957).

7. Donald R. 0lander, "Fundamental Aspects of Nuclear Reactor Fuel Elements," Nat"]. Tech. Info. Service (1976).

8. Hj. Matzke "Gas Release Mechanisms in $\mathrm{UO}_{2}$ ", Consultants

Symposium on Rare Gases in Metals and Ionic Solids, Harwe11, OK. (1979).

9. K. Malen, "Migration of I-131 in Fuel Rods," IAEA Technical Committee - Specialists' Meeting on "Internal Fuel Rod Chemistry," Erlangen, Germany, January (1979).

10. Table of Isotopes, 7th Edition, C. M. Lederer and V. S. Shirley, eds., Wiley-Interscience (1978). 